\title{
Teaching Subtitling at Jordanian Universities: An Untapped Territory
}

\author{
Ula K. Al-Dabbagh \\ Department of English, University of Petra, Amman, Jordan
}

\begin{abstract}
The impact of globalization and the advent of satellite channels and digital technology have played an instrumental role in changing the audiovisual translation scene in Jordan. During the last two decades, the subtitling industry has flourished at an exponential rate as manifested in the number of institutions engaged in this form of translation, the quantity of multimodal texts commissioned for translation and the widening remit of translation activities conducted under the rubric of subtitling. The marked development in the subtitling industry, however, has not received adequate support from the academic institutions in the country. Departments that award undergraduate degrees in translation rarely teach courses in subtitling, and research conducted on the pedagogy of this kind of translation is almost nonexistent. This paper argues that courses in subtitling should be incorporated in the translation studies curricula offered at Jordanian universities not because these courses are an embellishment but because the benefits accrued from teaching this mode of translation are multifaceted. The paper highlights these benefits and examines whether the feedback from students exposed to subtitling activities reflects the importance of integrating this mode of audiovisual translation in BA translation programs offered at Jordanian universities.
\end{abstract}

Index Terms - audiovisual translation, subtitling, translation studies curricula at Jordanian Universities, subtitling industry in Jordan

\section{INTRODUCTION}

In the 1990s, a proliferation of academic institutions in Jordan introduced undergraduate programs in translation studies to meet the growing market demand for professional translators. Prior to this shift in perspective, courses in translation offered at the university level were not only taught under the rubric of the English Departments but they also assumed an ancillary role in their curricula. The type of training students received overlooked the importance of theory in translation, and the practical component focused on the production of "acceptable" target language texts. ${ }^{1}$ Although the translation skills which students acquired were not multifarious, they were sufficient enough to meet the market demands prevalent at the time.

Such skills, however, gradually became inadequate in the early 90s as Jordan started witnessing the impact of globalization and the advent of satellite channels and digital technology. To provide the workplace with would-beprofessional translators that have "more marketable skills," universities had to advocate systematic training in translation, and hence the surge in interest in the discipline of translation studies at Jordanian institutions of Higher Education.

Although the systematic training of translation has come a long way since the instigation of the first BA programs in translation, the translation curricula have failed to keep abreast of the developments which the translation industry has witnessed during the past two decades. The courses are mainly paper-based, teacher-centered and overlook the new technological developments that have started to dominate the translation activities in the workplace.

Against this backdrop, this paper argues that courses in subtitling should be included in the curricula of translation departments at Jordanian universities because the "academization" of this form of translation is expected to equip trainee translators with the skills needed by the flourishing Jordanian audiovisual translation market. It is envisaged that the impact of giving students the skills and training required of audiovisual translators will impinge on all the parties engaged in shaping the subtitling landscape in the country, namely the would-be-professional subtitlers, the translation departments and the subtitling industry. To this effect, the paper examines the multifaceted benefits that can be gained from teaching subtitling to trainee translators and sets out to investigate students' attitudes regarding the usefulness of integrating subtitling courses in their study plans.

\section{SUBTITLING: AN OVERVIEW}

Subtitling is a form of audiovisual translation. Audiovisual translation is the process of transferring multimodal texts from one language into another. Multimodal texts are unique in that they are made up of a range of "modes" such as sound, dialogue, images, language, movements, gestures, music, and written signs, which the translator has to take into account in the process of translation. The diversified "modes" or "channels" (Gottlieb, 2001) impose certain restrictions on the nature of the transfer process and, in turn, necessitate that audiovisual translators acquire certain skills that enable them to produce an end-product that can be easily assimilated by the receiving viewers. 
There are two types of audiovisual translation: the dominant and the challenging or assistive. The former includes interlingual subtitling, dubbing, voice-over, simultaneous interpreting and free commentary. The latter includes modalities, such as intralingual subtitling, audio description and surtitling (Gambier, 2003; Peréz-González, 2014). Although the aforementioned forms of audiovisual translation have found their way into markets in European countries, interlingual subtitling remains the most dominant form of audiovisual translation commissioned in the Arab world (Thawabteh, 2011a; Gamal, 2013).

Interlingual subtitling (henceforth subtitling) involves transferring audio-visual messages in language A into their corresponding written texts in language B; the text in language B is usually presented at the bottom of the screen and has to appear simultaneously with the verbal messages originally expressed in language A.

Unlike the traditional print text-type translation, which renders written texts in the source language into their equivalent written versions in the target language, subtitling works between two "channels" or "modes": the audiovisual on the one hand, and the written on the other. In such a scenario, where the spoken medium is transmitted to the receiving audience in the form of a written medium, subtitling, according to Gottlieb (2004a, p. 220), is considered a "diagonal diasemiotic" translational practice which involves two opposite codes (the spoken vs. the written), and hence stands in contradistinction with the "horizontal isosemiotic" translational practice that is confined to the written channel

Ostensibly, the "jaywalking from source-language speech to target-language writing" (ibid.) may seem simple, but in reality it is fraught with constraints. Needless to say, rendering the visual and acoustic channels on a limited screen area "solely through writing" (Gottlieb, 2004b, p. 86) creates technical restrictions that dictate the working strategies which subtitlers adopt.

Scholars (Delabastita, 1989; Gottlieb, 1992, 2001; Chiaro, 2009; among others) highlight two technical "constraints" or "restrictions" associated with subtitling: spatial and temporal. The spatial constraints result because subtitles are superimposed on a restricted space area that occupies a pre-set position on the screen. To fulfill these layout standards, subtitles do not usually exceed two lines and each line is made up of 30 to 40 characters (Gottlieb, 2001; Chiaro, 2009; Díaz Cintas \& Remael, 2007). The temporal constraints have to do with the exposure time allotted to each subtitled line. Taking into consideration that subtitling involves a shift from the spoken code into the written code, subtitles have to appear simultaneously with the dialogue on the screen, and they have to be left on display "at a pace not exceeding 12 characters per second" to enable viewers to read the subtitles comfortably (Gottlieb, 2004a, p. 219).

The aforementioned technical constraints impose a number of limitations on the amount and nature of information that appears on the screen, and hence the translation strategies adopted by subtitlers. Antonini (2005, p. 213-214) acknowledges that because of these constraints "the subtitler must reduce the translated text by carrying out three main operations: elimination, rendering and simplification." These translation strategies and the technical processes involved in subtitling, such as spotting, cueing, time-coding, editing, proofreading and working knowledge of the software, ${ }^{2}$ indicate that subtitlers have to be cognizant of the intricacies of subtitling in order to secure successful reception of the subtitled target texts that they produce. To achieve this goal, future subtitlers have to be provided with systematic training in this domain.

\section{The ACADEMIZATION OF Audiovisual TransLATION}

In Europe, scholarly interest in the different forms of audiovisual translation is relatively new. Before the 1990s, audiovisual translation was overlooked by scholars and researchers working in the field of translation studies, and some did not even consider it worthy of study because of the spatial and temporal constraints that dictate the techniques used in the production of the target texts. Some went a step further and considered this activity a form of "adaptation" and not proper translation (Fawcett, 1996; Díaz Cintas, 2008).

The marginalization of audiovisual translation, however, did not persist for long because the audiovisual translation landscape gradually started to witness changes on the academic front as of the mid-1990s (Gambier, 2003; Orero, 2004; Pérez-González, 2014; among others). A number of factors contributed to the change in perspective regarding this form of translation, but the advent of digital technology is considered the most significant (Orero, 2004).

Needles to say, such a development called for the training of specialists in screen translation to meet the growing market demand for this kind of translation. Before long, courses in screen translation or audiovisual translation, as it is referred to today, started to spread in European universities in Spain, Portugal, Denmark, Sweden, Finland, Italy, Germany and the UK; institutions in Brazil, India and South Africa followed suit soon after (Kruger, 2008). Not surprisingly, the proliferation of courses in audiovisual translation resulted in an increase in the number of conferences held to discuss the topic, the quantity and quality of academic research published in the field and the academic books made available to academics and researchers involved in the teaching and training of future audiovisual translators (Pérez-González, 2014).

These developments, however, have not been observed within the Arab academic context, and Jordan is no exception. Although the Arab world is considered a high-profile subtitling region, this form of audiovisual translation, as well as other forms, such as dubbing and voice-over, are still largely ignored in the curricula of departments that offer BA degrees in translation studies (Thawabteh, 2011b). Gamal (2013, p. 366-367) states that audiovisual translation is looked upon by "many academics in the Arab world as a European vogue," and hence it remains, to date, an "outlandish" activity in academic circles. ${ }^{3}$ 
The lack of interest in audiovisual translation, in general, and subtitling, in particular, is clearly attested in the scarcity of taught courses in this field. In Jordan, the translation study programs focus mainly on written translation, with one or two courses in consecutive and simultaneous interpreting, and students receive training in translating journalistic, legal, literary, economic, religious and scientific texts after successfully completing two courses in general translation. ${ }^{4}$ Out of the twelve universities that offer BA degrees in translation studies, only two teach modules in audiovisual translation, namely Yarmouk University and the German-Jordanian University. Both courses "Translating Films and Documentaries" and "Audiovisual Translation and Electronic Tools" are elective modules which means the respective department is not obliged to offer the course if it deems this necessary. As a result, students majoring in translation studies at the abovementioned universities, like their counterparts in other universities, might graduate without receiving theoretical or practical training in subtitling or any of the forms studied under audiovisual translation.

The modest standing of subtitling at Jordanian universities might be attributed to a number of reasons. First, many of the professors who teach translation are unfamiliar with the technicalities of subtitling and generally express disinterest in this form of translation. Second, academic institutions are not willing to invest in the subtitling software nor are they willing to recruit expertise in the field for a single elective course. Third, the lack of cooperation between academia and the subtitling industry has obscured the growing importance of subtitling in Jordan.

Research in subtitling has not fared any better at Jordanian universities. Academics affiliated to these institutions have not given justice to this form of audiovisual translation. On examining the résumés of thirty academics who teach translation at these universities, it is apparent that research in subtitling, and other modes of audiovisual translation, is not within the realm of their research interests in comparison with the research they have conducted on other issues pertaining to translation studies. Also, a survey of articles published in Meta: Translators' Journal and AWEJ (Arab World English Journal), respectively further confirms the academic circles' disinterest in audiovisual translation since none of the articles published in this area are by scholars who work at Jordanian universities.

It is, therefore, not surprising that in view of the current state of affairs, translation conferences held in Jordan have ignored themes pertaining to subtitling or any other form of audiovisual translation. During the Fifth International Conference of the Association of Professors of English and Translation at Arab Universities held in 2015, out of the seventeen papers presented under the theme "Language instruction and translation," only one addressed subtitling. Unfortunately, no change in perspective seems imminent; the themes that are to be discussed during the Sixth International Conference of the Association of Professors of English and Translation at Arab Universities to be held in 2017 do not explicitly address topics associated with audiovisual translation. This is a clear indication that interest in audiovisual translation is lagging behind in Jordan. Unless academics working at the institutions of higher education that offer BA programs in translation studies at Jordanian universities come to the realization that the teaching and training of subtitling can be beneficial to all the parties involved in the field of translation, and act accordingly, the gap between academia and the workplace will continue to grow.

This lack of harmony between academia and the industry needs to be resolved because the subtitling industry in Jordan has been witnessing remarkable changes since 1999 when Rosetta International, the first private subtitling company, was launched to meet the pressing need for professional subtitlers. Since its inception, the company has provided subtitling, dubbing and copyediting services to a diversified body of clients and has "successfully and singlehandedly established the TV subtitling industry in Jordan” (http://www.rosettainternational.net).

Since 1999, the number of hours commissioned for subtitling in Jordan has increased significantly making Amman "one of the major centres of AVT work in the Arab world today" (Gamal, 2007, p. 126). To meet the number of hours commissioned for subtitling, there has been an increase in the number of companies that specialize in audiovisual translation. Companies like Captivate Arabia, Titras, Context Writing Services and Publishing House, Jordan Translate Services and Dar Ibn Khaldoun for Translation, among others provide services in subtitling, dubbing and voice-over, and some, like Captivate Arabia also offer compliance editing services. These companies subtitle films, documentaries, interviews, news pieces and cartoons and employ full-time, part-time and freelance subtitlers to meet deadlines. Their clients include agencies such as the Middle East Broadcasting Center (MBC), Orbit Showtime Network (OSN) and Dubai Media Incorporated (DMI), to name just a few.

The increase in the number of subtitling companies and the rise in subtitling commissions has created a pressing need for professional subtitlers. According to professionals engaged in the subtitling market, the subtitling industry can provide employability to $70 \%$ of the BA translation program graduates if they are well-equipped to meet the demands of the industry; unfortunately, academia has so far failed in fulfilling this end-result. To overcome this daunting situation, the academic circles have to re-evaluate the translation study plans currently offered at the tertiary educational level and consider adding subtitling, and other courses in audiovisual translation, to facilitate the integration of novice translators in the subtitling industry.

\section{Teaching Subtitling to Trainee Translators: A Multifaceted Activity}

The peripheral role that subtitling occupies in the translation studies curricula at Jordanian universities indicates academics' and policymakers' indifference to the advantages that can be gained from teaching this mode of translation. In what follows, these advantages are highlighted to arouse interest in subtitling and to pave the way for future empirical research in this field of translation. 


\section{A. Initial Training for Future Subtitlers}

Although subtitlers have to possess the linguistic, textual, analytical, cultural, and contextual competencies employed by translators working with other modes of translation, subtitlers have an additional burden of applying these competencies "within very rigid constraints of time and space, while adhering to specific conventions of quality and form" (Kruger, 2008, p. 82). Such a setup requires that translators working in subtitling be cognizant of the diversified techniques, strategies and skills involved in the production of subtitled target language texts because as Kruger (ibid.) rightly states "mastering and applying these skills take a long time."

Therefore, introducing one or two subtitling courses in the curricula of translation studies programs can at least equip students with the initial training that will provide them with the insights needed in the workplace. This is of paramount importance for two main reasons. The first reason is that many students do not have a clue about the intricacies of this kind of translation. When I asked fifty third and fourth year students majoring in translation at different universities in Jordan to summarize what they know about subtitling, the answers I received were general in nature. Although all the students $(100 \%)$ defined subtitling as a form of translation that appears on screens, only $8(16 \%)$ mentioned technical features pertaining to subtitling like "synchronization" and "constraints." The second reason for integrating subtitling courses in translation programs is the feedback received from professionals working in the subtitling industry who have expressed that novice translators do not always have the suitable skills for the subtitling jobs available on the market; consequently, subtitling firms find themselves compelled to give these recruits extensive training before they start their subtitling tasks, which is both costly and time-consuming.

To overcome the aforementioned flaws, the content of a course in subtitling can address both the theoretical and the practical aspects of subtitling, with a suggested ratio of $30 \%$ theory and $70 \%$ practice. This ratio is in line with the course content of audiovisual translation modules at European universities which "typically favours practice over theory" ((Díaz Cintas \& Orero, 2003, p. 372). More emphasis should be given to the practical component because the course should provide students with initial training in subtitling before they join the workforce. A variety of teaching techniques that include lectures, seminars, and both in-class and hands-on practice should be adopted to achieve this aim.

\section{B. Fosters Translation Skills}

Research on the pedagogical impact of using subtitling in enhancing trainee translators' translation skills reveals that subtitling can be implemented to foster these skills with the help of authentic subtitled programs and/or subtitle creation exercises (Neves, 2004; Kiraly, 2005; McLoughlin, 2009). The former approach involves adopting authentic, readycaptioned programs in translation exercises, while in the latter approach students produce the subtitled material during and/or outside class hours with the help of subtitling software. Both methods enhance source and target language knowledge, foster text-type awareness, develop critical thinking and translation criticism and improve translation skills (McLoughlin, 2009).

The aforementioned approaches are expected to improve students' translation performance because the subtitling exercises introduce trainee translators to "new" translation strategies frequently employed in the transference of audiovisual texts, and at the same time, enhance the translation skills they had acquired in other translation courses. Students, therefore, practice how to produce comprehensible subtitled texts using an amalgam of translation strategies; in so doing, they see how different translation strategies are interrelated, and how they can be applied to a variety of texts to overcome translation problems. An outcome, as Kruger (2008, p. 87) says, can be fulfilled in "an exciting and engaging way" which endows an added value to courses in subtitling.

Another skill that can be enhanced with the inclusion of subtitling in translator training is translation criticism. When students criticize authentic subtitled programs as well as their own subtitles, subtitling can help in the "critical understanding of the translation process," can "provide criteria of analysis" and can "link that analysis to translation strategies" (McLoughlin, 2009, p. 181). All these skills combined are expected to make students realize that a solid foundation in theory is essential if translators and subtitlers do not want to base their translations on intuition.

Subtitling can also enhance trainee translators' understanding of the notion of genre (McLoughlin, 2009). Since programs that need subtitling include, not only films, but documentaries, interviews, reality TV shows and political speeches, the notion of genre is reiterated during the subtitling process. This is achieved by studying the lexical, structural, textual and pragmatic specificities of the aforementioned genres, and discussing the most suitable translation/subtitling strategies employed in transferring such features between English and Arabic and vice versa.

The importance of audience identification can also be emphasized through subtitling. The audience is a variable that has to be taken into consideration in the process of translating all text-types, but it is of paramount importance in subtitling. Students have to be taught that before they start subtitling, they have to know the audience they are addressing (children vs. adults; specialists vs. laymen) and the impact this has on the subtitling strategies they have to adopt. To this effect, Gambier (2003, p. 185) states that "the requirements of specific groups of viewers might allow the screen translator, for instance, to condense up to $35-40 \%$ of a film but less than $20 \%$ of a news program." Unless students practice how to achieve such a goal, positive audience reception might be jeopardized. Also, students have to realize that viewers of subtitled films and programs look for "communicative effectiveness and not artistic effect" 
(Neves, 2004, p. 135) which entails the use of specific subtitling strategies to ensure "successful" assimilation of the subtitled target text(s) by the receiving audience.

\section{Improves Foreign Language Learning}

The impact of integrating authentic subtitling programs in foreign language learning (FLL) has been discussed extensively by a number of scholars working with a variety of language combinations. The results of the studies confirm that using subtitling in foreign language classrooms can help improve students' listening comprehension (Danan, 2004), reading comprehension (Bravo, 2008), vocabulary learning (Baltova, 1999) and oral production (Borrás \& Lafayette, 1994).

The linguistic rewards gained from using authentic subtitled programs in FLL have encouraged researchers to investigate the usefulness of subtitle insertion activities in FLL classrooms. This has resulted in the introduction of subtitling software programs, like ClipFlair, a free online tool that allows students to learn a foreign language by adding their own subtitles to clips. ${ }^{5}$ The activities available simulate semi-professional subtitling environments whereby students use the ClipFlair platform to watch clips and insert their own subtitles based on their knowledge of the target language. Consequently, students practice the foreign language they are studying and become acquainted with the preliminaries of subtitling. The surveys conducted on ClipFlair reaffirm that subtitle insertion activities enhance foreign learners' linguistic skills and improve language learning motivation (Baños \& Sokoli, 2015).

Academics at Jordanian universities should take the positive results of integrating subtitling activities in FLL into consideration because the majority of students who specialize in translation at these universities are non-native speakers of English. They study English as a foreign language at school, and generally speaking, the students' receptive and productive skills in the language are average or below average upon joining the specialization; a weakness that can be addressed through training in subtitling.

\section{Develops Cultural and Ideological Awareness}

Scholars working in the field of translation have repeatedly emphasized that translation is an activity that involves transferring linguistic and cultural entities from one language into another. They have even described translators as "bicultural mediators" and as "couriers of culture" (Katan, 1999; Landers, 2001; respectively). These characteristics do not only apply to translators, but to subtitlers as well, who come across a multitude of cultural-specific terms when they have to transfer messages between two divergent cultures, like Arabic and English. Explaining to students, with the help of images and sounds, the recurrent cultural references that appear on audiovisual programs, and choosing the most suitable equivalents in the target language, help in enhancing students' cultural awareness and in the production of a subtitled output that succeeds in meeting the viewers' expectations (Borghetti \& Lertola, 2014).

Equally important in subtitling is the translation of ideology. Subtitling political interviews, speeches and programs can develop students' ideological awareness, for they get to see how patronage and political bias work in real life circumstances. Analyzing subtitled political programs, for instance, helps students understand how the political agendas of the commissioning agent(s) dictate the translation strategies used in the act of subtitling; they learn why and under what conditions a term like the "Islamic State" is rendered as $\square$ is abet dāeš (Daesh Gang) in some contexts, but as addawla al-islämiya (Islamic State) in others. This is of paramount importance in professional settings where compliance editing is one of the services offered by subtitling firms.

\section{Students' Reflections on the Benefits of Teaching SubTitLing to Trainee Translators}

\section{A. Methodology}

This section explores students' attitudes regarding the benefits of teaching subtitling to trainee translators and the need to incorporate subtitling courses in the translation curricula at Jordanian universities. To fulfill this goal, 20 students majoring in translation at the University of Petra were briefly introduced to the technicalities of subtitling and were given practical subtitling activities as part of a course entitled "Theories of Translation."

The taught material consisted of a theoretical and a practical component. In the theoretical component, students were briefly introduced to a number of points. First, they were introduced to the different kinds of subtitling (interlingual vs. intralingual). Second, the distinctive features that operate in subtitling were explained (spatial and temporal constraints) and the impact these constraints have on the linguistic, semantic, pragmatic and cultural dimensions of the target language text(s) were pointed out. The most common translation strategies employed, such as "reduction," "omission," "neutralization," and "expansion" (Gambier, 2003, p. 183) were discussed and examples of these strategies were analyzed. Third, students were acquainted with the technicalities and conventions of subtitling (synchronization, spotting and segmentation, typeface).

In the practical component, students were asked to watch, analyze and criticize authentic subtitled programs, and they also had to produce their own subtitles. Since twelve contact hours were allotted to the material taught on subtitling, the practical activities were limited and were completed outside the classroom; the students' work, however, was discussed and analyzed during classes. Although students were introduced to the free software program, Subtitle Workshop (version 2.51), and used it for the subtitling tasks, most of the practical activities were done on paper to overcome the 
technical problems students encountered. In producing the subtitled print versions, students had to take into consideration the spatial and temporal constraints associated with subtitling.

Upon completion of the theoretical and practical components, students were asked to answer a questionnaire consisting of 12 statements; the three response anchors "Agree," "Don't Know," and "Disagree" were adopted. The statements were structured based on the benefits of teaching subtitling discussed in prior research as well as the theoretical and practical material covered during the implementation of the study. To test the reliability of the students' responses, and to get a clearer picture about the reasons underlying their choices, students' answers were discussed with them on an individual basis. The following statements were used to measure the students' attitudes:

1) Subtitling provides initial training for the workplace

2) Subtitling improves translation skills

3) Subtitling improves translation criticism

4) Subtitling enhances the understanding of the notion of genre

5) Subtitling enhances the understanding of the notion of audience identification

6) Subtitling improves language skills

7) Subtitling improves vocabulary acquisition

8) Subtitling improves listening skills

9) Subtitling improves writing skills

10) Subtitling enhances cultural awareness

11) Subtitling enhances ideological awareness

12) Subtitling courses should be integrated in the BA translation study programs at Jordanian universities

\section{B. Analysis}

The students' feedback regarding the benefits gained from teaching subtitling was positive, confirming the results reached in previous research. In what follows, the students' responses are presented in Table 1; then their responses and opinions are discussed.

TABLE 1

STUDENTS' REFLECTIONS ON THE BENEFITS OF TEACHING SUBTITLING

\begin{tabular}{|l|l|l|l|l|}
\hline STATEMENTS & AGREE & DON'T KNOW & DISAGREE \\
\hline 1 & $\begin{array}{l}\text { Subtitling provides initial training for the } \\
\text { workplace }\end{array}$ & 15 & 5 & 0 \\
\hline 2 & Subtitling improves translation skills & 18 & 2 & 0 \\
\hline 3 & Subtitling improves translation criticism & 17 & 0 & 3 \\
\hline 4 & $\begin{array}{l}\text { Subtitling enhances the understanding of } \\
\text { the notion of genre }\end{array}$ & 10 & 0 & 10 \\
\hline 5 & $\begin{array}{l}\text { Subtitling enhances the understanding of } \\
\text { the notion of audience identification }\end{array}$ & 0 & 2 & 18 \\
\hline 6 & Subtitling improves language skills & 20 & 0 & 0 \\
\hline 7 & $\begin{array}{l}\text { Subtitling improves vocabulary } \\
\text { acquisition }\end{array}$ & 20 & 0 & 0 \\
\hline 8 & Subtitling improves listening skills & 20 & 0 & 0 \\
\hline 9 & Subtitling improves writing skills & 11 & 0 & 9 \\
\hline 10 & Subtitling enhances cultural awareness & 20 & 0 & 0 \\
\hline 11 & $\begin{array}{l}\text { Subtitling enhances ideological } \\
\text { awareness }\end{array}$ & 14 & 0 & 6 \\
\hline 12 & $\begin{array}{l}\text { Subtitling courses should be incorporated } \\
\text { in the BA translation study programs at } \\
\text { Jordanian universities }\end{array}$ & 15 & 0 & \\
\hline
\end{tabular}

\section{Statement (1)}

In their evaluation of the course content and whether they thought the material taught had provided them with initial training for the industry, 15 students $(75 \%)$ chose "agree" because the activities had introduced them to the "basics" of subtitling. They felt that they would not be a "blank page" if they decided to work for a subtitling firm. The 5 students (25\%) who chose "don't know" said they needed to be cognizant of the working conditions to be able to judge the effectiveness of the material taught for the subtitling market.

\section{Statement (2)}

18 students (90\%) agreed that subtitling exercises can help "fine-tune" their translation skills; the remaining 2 students (10\%) said they did not know whether this mode of translation was rewarding in this respect. According to the 18 students, exposure to a variety of ready-captioned programs and subtitle insertion tasks are beneficial for two reasons: (1) they can inadvertently improve students' translation skills since they get to see how subtitlers have tackled translation problems; and (2) engagement in subtitling is, first and foremost, a translation exercise which entails more practice in translation. However, all the students were of the viewpoint that the practical component was more of a "warm-up" exercise that needed to be reinforced in fully-fledged subtitling courses.

Statement (3) 
After criticizing a subtitled episode of National Geographic in order to identify the good and weak points noted in the Arabic subtitled version, 17 students $(85 \%)$ expressed that they "agree" that subtitling develops translation criticism, and the remaining $3(15 \%)$ opted for "disagree." The 17 students who thought subtitling can improve translation criticism said the exercise had proved useful on several counts: (1) their critical abilities had been put to the test; (2) they had applied what they had studied in "Theories of Translation" to criticize and correct the weaknesses and/or errors they had identified in the translated output; and (3) correcting the flaws in the Arabic subtitled version had helped them practice translation. The students said that criticizing subtitled products had clarified in a "simple" and "interesting" way how translation theory could provide them with the guidelines needed in solving translation problems. The 3 students who did not think the integration of subtitling had a positive effect on their criticism abilities stated they had encountered problems understanding the English version of the episode, and this had made the exercise difficult to implement and assess.

\section{Statement (4)}

As far as genre identification is concerned, 10 students (50\%) chose "agree" that subtitling can enhance their understanding of the notion of genre, while 10 students $(50 \%)$ chose "disagree." The students who opted for "agree" reported that the notion of genre was "easier" to understand, and to tackle in translation, when reference is made to multimodal texts because such texts are "simpler" to translate in comparison with written texts. The students who chose "disagree" said they had always found genre identification difficult, and had disregarded this aspect while working on the subtitling activities. The students' feedback indicates that more attention needs to be given to the notion of genre in the translation courses offered at the department.

\section{Statement (5)}

With regards to audience identification, the responses were surprising. 18 students (90\%) did not consider subtitling a useful medium for audience identification, for they chose "disagree;" they commented that they had not taken this aspect into consideration when they worked on the subtitling activities. The remaining 2 students (10\%) chose "don't know" and were incapable of explaining their choice. The students' responses might be attributed to the fact that the significance of audience identification in the process of translation is ignored in the written translation courses taught at the department.

\section{Statement (6)}

To test whether trainee translators' language skills can be consolidated using ready-captioned programs and subtitle insertion activities, the students were given two assignments: (1) to watch four subtitled episodes of The Doctors; and (2) to subtitle a ten-minute film scene, interview or news piece. After completing the subtitling activities, all the students $(100 \%)$ reported that subtitling activities, if well-designed, could be beneficial for language learning.

\section{Statement (7)}

There was unanimous agreement among the students that subtitling can improve vocabulary acquisition. All the students (100\%) agreed that watching four subtitled episodes of The Doctors had added new vocabulary items to their vocabulary repertoire, and they were of the viewpoint that the Arabic subtitles had helped them understand many of the unfamiliar vocabulary items used in the episodes; the activity made them realize that they had an insufficient medical/scientific vocabulary item bank and that they needed to do something about this weakness.

\section{Statement (8)}

All the students $(100 \%)$ agreed that listening can be developed through training in subtitling. Since subtitling relies extensively on listening, students commented that more exposure to a variety of accents and speaking speeds was expected to help them improve their listening skills. They added that listening comprehension related problems had hampered their understanding of the verbal messages conveyed in the programs they had watched, and this had a negative impact on their subtitling performance.

\section{Statement (9)}

Students' responses differed concerning the usefulness of adopting subtitling for developing writing skills. Only 11 students (55\%) chose "agree," and they pointed out that reproducing the verbal messages in clear writing had been the most difficult activity in the subtitling process since the limitations of space and time made them write and rewrite the subtitles a number of times before they could produce a comprehensible message in the target language. The students' comment is not surprising because subtitling which involves "turning the spoken word into written strings that are rich enough to convey a multitude of meanings and yet simultaneously straightforward and clear" (Neves, 2004, p. 136) requires trainee subtitlers to have a perfect command of the target language; something that many of our future subtitlers do not necessarily possess. The remaining 9 students $(45 \%)$ who chose "disagree" reported that writing skills could only be improved when students practice writing paragraphs and essays; in their point of view, adding one or two lines did not help in developing their writing skills.

\section{Statement (10)}

As far as cultural awareness is concerned, the 20 students (100\%) thought that subtitling develops intercultural knowledge. In their opinion, exposure to unfamiliar cultural codes had introduced them to novel cultural terms; it had also made them realize how demanding the translation of culture can be, and the multilayered translation skills subtitlers need to possess to solve many of the cultural mismatches prevalent in texts that need subtitling. 12 students 
(60\%) said that watching subtitled programs had helped them understand how strategies, like "exoticism," "calque" and "cultural borrowing," which they had been introduced to during the course, had been used in authentic contexts.

\section{Statement (11)}

After watching ready-captioned political interviews, 14 students (70\%) agreed that subtitling could develop ideological awareness. They reported that subtitling, like other forms of translation, was not always an "innocent" activity, but one that is sometimes governed by a diverse number of political agendas. The subtitled interviews made them realize how commissioning agents can tone down interviewees' point of view, ignore and/or twist their political opinions and use the terms that best suit the commissioning agents' ideological agendas. 6 students (30\%) opted for "disagree" because, in their opinion, ideological awareness is "complex" and cannot be "appreciated" via subtitling.

\section{Statement (12)}

Based on the subtitling activities conducted during the "Theories of Translation" course, 15 students (75\%) were in favor of integrating subtitling courses in the curricula of translation programs at Jordanian universities. They said that the activities had been an eye-opener to the subtleties of subtitling and had "encouraged" them to apply for jobs in the subtitling industry after graduation. The remaining 5 students $(25 \%)$ said they preferred written translation and "did not really care" if subtitling courses were to be added to their study plans.

Although the students' reflections are based on a study that was conducted over a limited period of time, they reaffirm the multifaceted benefits gained from teaching subtitling to trainee translators. Similar studies are encouraged to further substantiate the importance of teaching subtitling at Jordanian institutions of Higher Education.

\section{CONCLUSION}

Although Jordan is a high-profile subtitling country, translation departments that offer BA degrees in translation studies at Jordanian universities have not given this form of audiovisual translation adequate attention. Modules in subtitling are rarely offered at the undergraduate level, and research in the field remains scant. This paper argues that it would be a good investment to add subtitling courses in our curricula because the benefits accrued from teaching such courses are multifaceted.

First, teaching subtitling gives students initial training in subtitling and prepares them for the profession. After all, the majority of departments that offer translation courses state on their websites that they prepare their students for the workplace. Statements like "the department prepares students for a career in translation" (www.uop.edu.jo/En/Academic/FacultuArts), and the department aspires to produce "skilful and competent graduates to the job market" (www.arts.yu.edu.jo/en/translation) are examples of some of the goals departments aspire to fulfill. Undoubtedly, these goals cannot be achieved if the courses offered do not meet the demands of the translation market.

Second, since subtitling is a form of translation, well-devised exercises in subtitling are expected to enhance students' translation skills. When students subtitle, they have to draw upon the knowledge they had gained in the written translation courses, as well as the knowledge they had acquired in the subtitling course(s).

Third, subtitling can foster students' foreign language learning skills. Subtitling can improve students' receptive and productive skills since most of the students join translation departments with only a formal knowledge of English.

Fourth, subtitling can develop students' cultural and ideological awareness. Exposing students to cultural and ideological issues through subtitling adds a touch of authenticity to ideas that are otherwise tackled in a theoretical manner during "traditional" translation classes. Implementing the theories associated with the translation of culture and ideology to authentic texts makes the exercise more challenging and less theoretical.

The students' feedback regarding the usefulness of teaching subtitling courses to trainee translators echoes the results reported in previous research and further confirms that teaching subtitling can be a rewarding experience on a number of fronts.

Students noticed that subtitling can help develop their translation and linguistic skills in an enjoyable way. They reported that subtitling could foster students' translation skills and critical abilities; could facilitate students' understanding of the notion of genre; and could develop students' cultural and ideological awareness. On the linguistic level, they stated that subtitling could improve trainee translators' listening and writing skills and develop their acquisition of vocabulary. Although students did not highly rate subtitling as an effective tool for fostering audience identification, this might be attributed to the teaching methodology adopted by the members of staff which does not emphasize this issue in the written translation courses. The results of the study were also rewarding on the professional level. Two of the graduating students applied for subtitling posts at a subtitling company and have been offered jobs after graduation. It is my contention that the students' attitudes should encourage the academic circles at Jordanian universities to follow the footsteps of their counterparts elsewhere and introduce subtitling, and other forms of audiovisual translation, in the curricula of undergraduate translation study programs.

\section{Notes}

1. The information about the translation courses is based on feedback from graduates of English Departments at Jordanian universities during the 1970s and 1980s.

2. For a detailed account of these activities see Jorge Díaz Cintas and Aline Remeal (2007).

3. This specifically applies to undergraduate programs in translation studies. 
4. Due to the limitations of space, the translation programs offered at all the Jordanian universities cannot be discussed in this paper. Reference to sample programs can be found on the following websites: University of Petra (www.uop.edu.jo/En/Academic/FacultuArts), Jadara (www.jadara.edu.jo/reghome/plans/plan20\%of\%20translationplan.pdf) and Zarqa University www.zu.edu.jo/en/College/Arts?Dept Translator Arts/GetStudyPlan.aspx?id=4

5. For more information visit http://studio.clipflair.net

\section{REFERENCES}

[1] Antonini, R. (2005). The perception of subtitled humor in Italy. Humor 18.2, 209-225.

[2] Baltova, I. (1999). Multisensory language teaching in a multidimensional curriculum: The use of authentic bimodal video in core French. The Canadian Modern Language Review 56.1, 32-48.

[3] Baños, R. \& S. Sokoli. (2015). Learning foreign languages with ClipFlair: Using captioning and revoicing activities to increase students' motivation and engagement. In K. Borthwick, E. Corradini \& A. Dickens (eds.), 10 years of the LLAS elearning symposium: Case studies in good practice. https//reference.research-publishing.net/publication/chapters/978-1-908416-230/280.pdf (accessed 1/7/2016).

[4] Borghetti, C. \& J. Lertola. (2014). Interlingual subtitling for intercultural language education: A case study. Language and Intercultural Communication 14.4, 423-440.

[5] Borrás, I. \& R. C. Lafayette. (1994). Effects of multimedia courseware subtitling on the speaking performance of college students of French. Modern Language Journal 78, 61-75.

[6] Bravo, C. (2008). Putting the reader in the picture: Screen translation and foreign language learning. Ph.D. dissertation, Universitat Rovira iVirgili. www.sub2learn.ie/download/tesicondhino.pdf (accessed 10/4/2015).

[7] Chiaro, D. (2009). Issues in audiovisual translation. In J. Munday (ed.), The routledge companion to translation studies. London \& New York: Routledge, 141-165.

[8] Clifford, L. E. (2001). Literary translation: A practical guide. Clevedon: Multilingual Matters.

[9] Danan, M. (2004). Captioning and subtitling: Undervalued language learning strategies. Meta 49.1, 67-77.

[10] David, K. (1999). Translating cultures. An introduction for translators, interpreters and mediators. Manchester: St. Jerome.

[11] Delabastita, D. (1989). Translation and mass communication: Film and TV translation as evidence of cultural dynamics. Babel 34.4, 193-228

[12] Diaz Cintas, J. (2008). Introduction: The didactics of audiovisual translation. In J. Diaz Cintas (ed.), The didactics of audiovisual translation. Amsterdam \& Philadelphia: John Benjamins, 1-18.

[13] Diaz Cintas, J. \& P. Orero. (2003). Postgraduate courses in audiovisual translation. The Translator 9.2, 371-388.

[14] Diaz Cintas, J. \& A. Remael. (2007). Audiovisual translation: Subtitling. London \& New York: Routledge.

[15] Fawcett, P. (1996). Translating film. In H. T. Geoffrey (ed.), On translating French literature and film. Amsterdam: Rodopi, 65-88.

[16] Gamal, M. Y. (2007). Audiovisual translation in the Arab world: A changing scene. Translation Watch Quarterly 3.2, 78-126.

[17] Gamal, M. Y. (2013). Audiovisual translation in the Arab world. http://www.iafor/archives/offprints/acah2013-offprints (accessed 10/5/2015).

[18] Gambier, Y. (2003). Introduction: Screen transadaptation: Perception and reception. The Translator 9.2, 171-189.

[19] Gottlieb, H. (1992). Subtitling: A new university discipline. In C. Dollerup \& A. Loggergard (eds.), Teaching translation and interpreting: Training, talent and experience. Amsterdam \& Philadelphia: John Benjamins, 161-170.

[20] Gottlieb, H. (2001). Subtitling. In M. Baker (ed.), Routledge encyclopedia of translation studies. London \& New York: Routledge, 244-248.

[21] Gottlieb, H. (2004a). Subtitles and international anglification. Words of words: A tribute to Arne Zettersten. Nordic Journal of English Studies 3.1, 219-230.

[22] Gottlieb, H. (2004b). Language-political implications of subtitling. In P. Orero (ed.), Topics in audiovisual translation. Amsterdam \& Philadelphia: John Benjamins, 83-100.

[23] Jadara University Website. www.jadara.edu.jo/reghome/plans/plan20\%of\%20translationplan.pdf (accessed 10/12/2015).

[24] Katan, D. (1999). Translating cultures: An introduction for translators, interpreters and mediators. Manchester: St. Jerome.

[25] Kiraly, D. (2005). Project-Based learning: A case for situated translation. Meta 50.4, 1098-1111.

[26] Kruger, J. (2008). Subtitler training as part of a general training programme in the language professions. In J. Diaz Cintas (ed.), The didactics of audiovisual translation. Amsterdam \& Philadelphia: John Benjamins, 71-88.

[27] Landers, C. E. (2001). Literary translation: A practical guide. Clevedon: Multilingual Matters.

[28] McLoughlin, L. I. (2009). Subtitles in translators' training: A model of analysis. Romance Studies 27.3, 174-185.

[29] Neves, J. (2004). Language awareness through training in subtitling. In P. Orero (ed.), Topics in audiovisual translation. Amsterdam \& Philadelphia: John Benjamins, 127-140.

[30] Orero, P. (2004). Audiovisual translation: A new dynamic umbrella. In P. Orero (ed.), Topics in audiovisual translation. Amsterdam \& Philadelphia: John Benjamins, vii-xiii.

[31] Pérez-González, L. (2014). Audiovisual translation: Theories, methods and issues. London \& New York: Routledge.

[32] Rosetta International Website. http://www.rosettainternational.net (accessed 8/1/2016).

[33] Thawabteh, M. (2011a). The translation of prosody and all that aggro: A case study of Arabic-English subtitling. T21N: Translation in Transition 2, 1-18.

[34] Thawabteh, M. (2011b). Linguistic, cultural and technical problems in English-Arabic subtitling. SKASE Journal of Translation and Interpreting. http://www.skase.sk/Volumes/JTI05/pdf.doc/02.pdf (accessed 8/4/2015).

[35] University of Petra Website. www.uop.edu.jo/En/Academic/FacultuArts (accessed 10/12/2015).

[36] Yarmouk University Website. arts.yu.edu.jo/en/translation (accessed 10/12/2015). 
[37] Zarqa University Website. www.zu.edu.jo/en/College/Arts?Dept_Translator_Arts/GetStudyPlan.aspx?id=4 (accessed $10 / 12 / 2015)$

Ula K. Al-Dabbagh earned her PhD in Translation Studies at Edinburgh University in the UK in 2003. She earned her Master's degree in Translation and Linguistics at Bath University in the UK in 1985.

She is currently an Assistant Professor of Translation and Linguistics at the Department of English, University of Petra, Jordan. She is also the Director of the Language Center. Her research interests include work on contrastive linguistics and literary and political translation. 